\title{
EVALUATION OF DIFFERENT COMPUTATIONAL MODELLING STRATEGIES OF A MASONRY VAULT WITH BUTTRESSES AND BACKFILL
}

\author{
FRANCESCA GOBBIN ${ }^{1}$, MARILAURA MALENA ${ }^{1}$, \\ GIANMARCO DE FELICE ${ }^{1}$ AND JOSE V. LEMOS ${ }^{2}$ \\ ${ }^{1}$ Roma Tre University-Department of Engineering \\ Via vito volterra 62, 00146 Rome, Italy \\ francesca.gobbin@uniroma3.it \\ marialaura.malena@uniroma3.it \\ gianmarco.defelice@uniroma3.it \\ ${ }^{2}$ LNEC-Dam Department \\ Av. Do Brasil 101, 1700-075 Lisbon, Portugal \\ vlemos@lnec.pt
}

Key words: Discrete Element Modelling, Finite Element Modelling, Catalan Vault, Masonry.

\begin{abstract}
In this paper, a critical comparison of two of the most common methods for the analysis of masonry vaults up to collapse is carried on. Innovative 2D Discrete Element (DE) and Finite Element (FE) models have been adopted aiming at capturing the main features of masonry single curvature structures mechanical behavior. Two numerical strategies are adopted: a discrete element model and a continuous homogenized model. The first approach provides an estimate of the collapse load and failure pattern of masonry based on ad-hoc implemented algorithm. The second approach is formulated in the framework of multi-surface plasticity and implemented in a FE code for the path-following non-linear analysis of masonry wall described as continuous anisotropic plate. The two numerical approaches are adopted to reproduce the Experimental Campaign of a full-scale Catalan vault with buttresses and backfill, statically loaded at $1 / 3$ span. The failure modes and the crack patterns obtained by the proposed models are compared between them and with that observed in the experimental test as well as the load-displacement response curves. Both the proposed models efficiently capture the behavior of the vault and, in particular, the backfill deformation and load-spreading effect, hinges position and formation order.
\end{abstract}

\section{INTRODUCTION}

The masonry architectural heritage is constituted by unique characteristics that make assessing its preservation particularly challenging. Due to their load-bearing capacity, masonry vaults have been widely used since Roman times in a large amount of historical construction. Despite its key role in modern restoration practice, assessing stability conditions of masonry 
curved structures is not a trivial task [1]. While the sole arch structural behaviour is only driven by the hinges creation, when the system involves backfill and abutments, mechanical behaviour is more sophisticated. Indeed, the load spreading effect of backfill and the increase of stiffness due to the presence of spandrel walls have a beneficial effect on the load bearing capacity of the structure [2].

Numerous numerical methods have been proposed for curved structures modelling. An accurate model of the structure should allow for the description of existing damage and alterations in the structure, including cracks, disconnections, crushing, deformation and damage evolution.

The selection of the most appropriate method to use depends on, among other factors, the desired level of accuracy and simplicity, knowledge of the input properties in the model and the computational load. Preferably, the approach selected to model the masonry should provide the desired information reliably within an acceptable degree of accuracy and at minimum cost. However, the selection of a suitable analysis method is not a trivial task.

In this paper, the result of a DEM model [3] and of a FEM model [4,5] are validated through the comparison of a full-scale experiment [6]. Collapse mode, crack pattern, hinge formation and load bearing capacity are shown and compared.

\section{THE EXPERIMENTAL SETUP}

The experimental campaign carried out in [6] consisted of one unreinforced vault and three externally reinforced vaults with shoukders, spandrel wall and backfith. The vauits were built with clay bricks and lime mortar, whilg the backfil consisted the vault.

The abutments were specimens were then s unloading cycles until failure
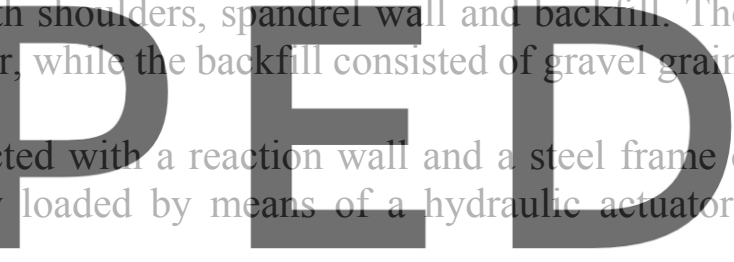
with 1 ts were buil
manually on
sides The
loading and

In this paper, only the unreinforced specimen is considered and the loading and unloading Register forcf feera

The experimental results provide a failure mode driven by four hinges located alternatively at the extrados and intrados of the vault. The load capacity was recorded at $5.8 \mathrm{KN}$ with the maximum displacement recorded at the two central hinges and consisting of $38.1 \mathrm{~mm}$ (upwards) and $36.1 \mathrm{~mm}$ (downwards).

\section{MODELLING APPROACHES}

Two bi-dimensional modelling strategy are herein adopted: the former, is based on a micromodelling approach, based on an Explicit Code [7], while the latter employs a continuous method $[4,5]$.

\subsection{Overview of modelling with DEM}

The Discrete Element Model is carried out by means of the commercial software UDEC [8]. Both rigid and deformable blocks are employed. The former, are adopted for the bricks, a part from the vault vossoirs, for which elastic bodies are modelled in order to increase the contacts discretization and the backfill, represented as a continuum elasto-plastic block (Figure 1).

In particular, each masonry unit is modelled considering the exact geometry and comprising 
half of the mortar joint on each side. Contacts represent the potential fracture lines, where cracking and sliding take place. At each edge of the interface, the constitutive behaviour is defined by non-linear springs located at each corner. In the normal direction, springs behaviour is purely elastic in compression and brittle in tension as far as the tensile strength, is overcome. In the tangential direction, the behaviour is governed by the Coulomb slip law:

$$
\tau \leq c+\sigma \cdot \tan (\varphi)
$$

Where $\tau$ and $\sigma$ are the shear and normal stresses, respectively, $\mathrm{c}$ is the cohesion and $\varphi$ is the friction angle. When the maximum stress is attained, the tensile strength and cohesion are reduced to zero and the behaviour in tangential direction is purely frictional. The input mechanical parameters for the contacts are: Normal stiffness $k_{n}$, Shear stiffness $k_{s}$, Friction angle $\varphi$, Tensile strength $f_{t}$ and Cohesion $c$.

The elastic normal stiffness at the contact between blocks $K_{n}$ is estimated from the Young moduli of both bricks $\left(E_{b}\right)$ and mortar $\left(E_{m}\right)$, by lumping at the contact the overall deformation as follows:
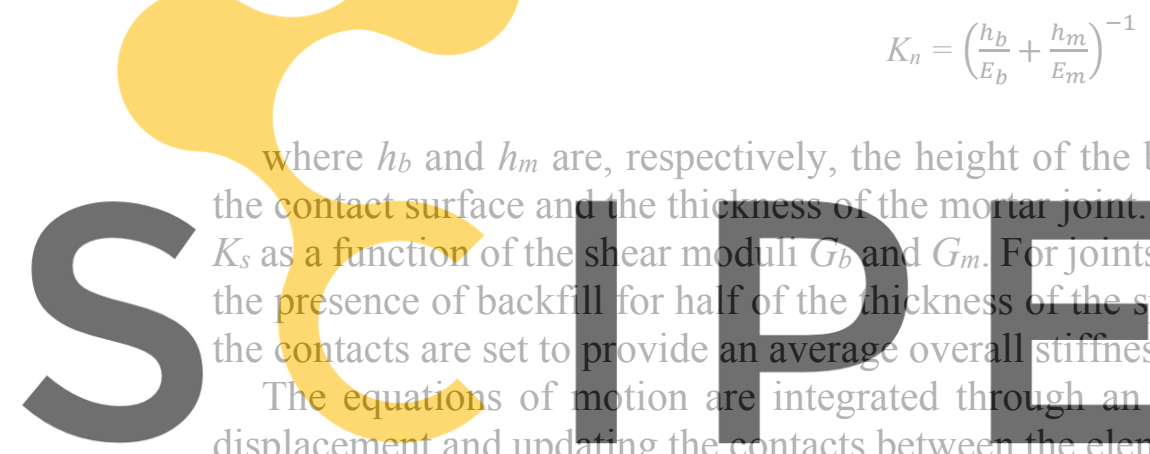

where $h_{b}$ and $h_{m}$ are, respectively, the height of the brick in the direction perpendicular to the contact surface and $K_{s}$ as a function of the sh the presence of backfill the contacts are set to $\mathrm{p}$ The equations of $\mathrm{m}$ displacement and updating the the thickness of the mortar joint. The s
shear moduli $G b$ and $G m$. For joints locat half of the thickness of the specim
provide an average overall stiffness betw
totion are integrated through an explic
ting the contacts between the elements same holds for the shear stiffness
med on the butresses, considering
ween masonry and backfill.
cit algorithm, considering finite the analysis.

Register for free at https//www.scipedia.com to download the version without the watermark 3.1.I Arch, Backfill and Load Model

According to the experimental setup, the vault is made of 25 rigid blocks which form the arch itself lying on the two abutments and constrained on both sides with buttresses. The live load is modelled through an ad hoc algorithm, in which the load cell is represented as a rigid block to which a constant vertical velocity, small enough to mitigate the effects of vibration, is applied. The resulting load is determined as the vertical reaction monitored at the contact between the block and the backfill.

The soil backfill is modelled as a Mohr Coulomb frictional no-cohesive and no-tension continuum deformable material, discretised with a triangular mesh grid having $30 \mathrm{~mm}$ average distance between the grid points. According to experimental tests, the mechanical parameters provided for the backfill are the density equal to $12 \mathrm{KN} / \mathrm{m}^{3}$ and the friction angle equal to $39^{\circ}$, whereas the Young's modulus and the Poisson's ratio for fine-grained soil are assumed respectively as $0.3 \mathrm{GPa}$ and 0.3 . An initial condition of a passive soil stress vertical gradient due backfill self-weight is applied, whereas dilatancy is neglected. In order to improve plasticity calculations and overcome the 'volumetric locking', the non-linear backfill behaviour is 
improved through the 'nodal mixed discretization' on stress, based on the averaging of volumetric strains and stresses in the elements around each node [9].

As regards, the strength properties of the joints, a constant friction angle of $31^{\circ}$ is adopted, while $f_{t}=0.2 \mathrm{MPa}$ and $c=0.3 \mathrm{MPa}$ are set at vault joints.

Blocks and joints belonging to the buttresses are modelled considering homogenised mechanical properties deriving from the bricks and the backfill. Furthermore, joints belonging to the interface between the vault and the backfill are modelled as frictional joints with $\varphi=39^{\circ}$, corresponding to the backfill friction angle. For further details of the numerical model, readers might refer to the cited work [3].

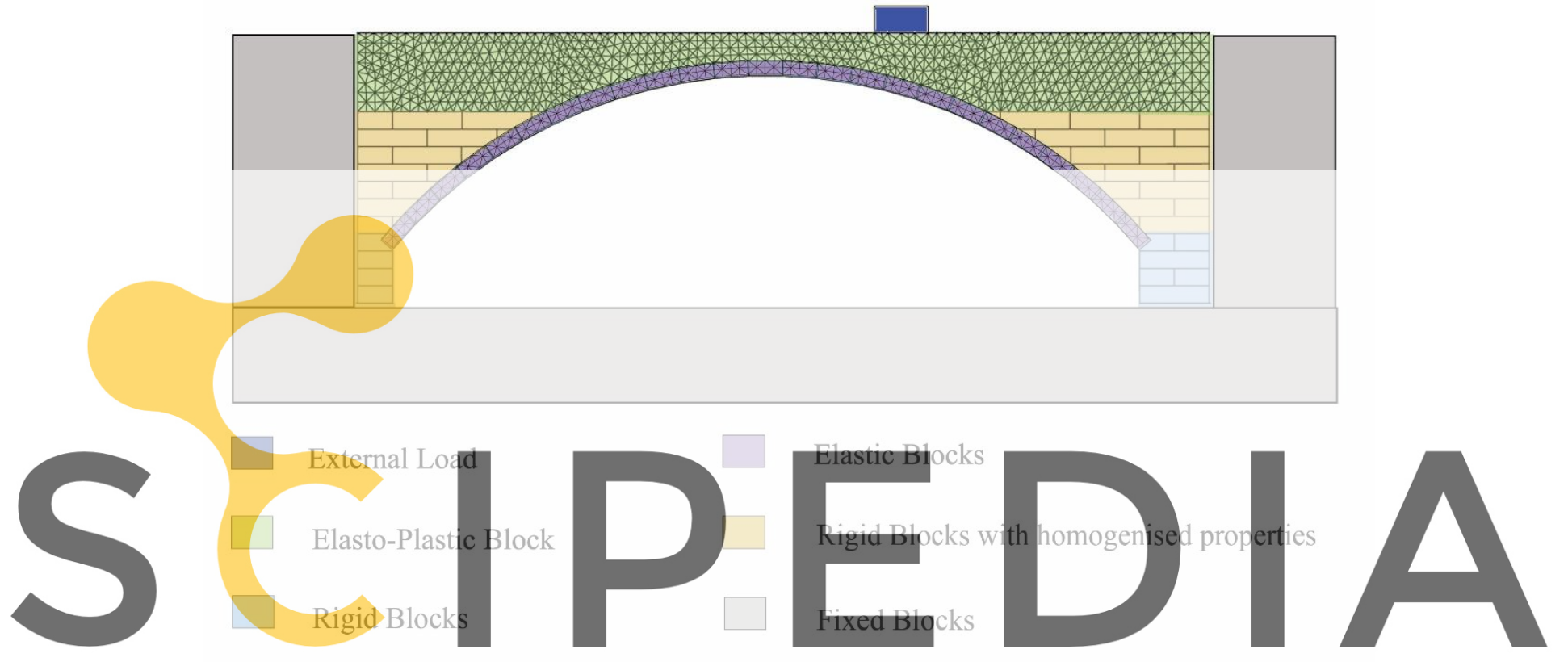

Figure 1. DEM Geometrical model.

\section{Register for free at https//www.scipedia.com to download the version without the watermark}

\subsubsection{Discrete Element Results}

The DEM failure configuration of the masonry vault are shown in Figure 2. The failure mode obtained from the numerical model matches perfectly to the experimental one for both the bricks displacement and the backfill deformation. In Figure 3 the load-displacement curve and is shown for the two proposed modelling strategies and compared with the experimental data. The shown sownword displacement is recorded between block 16 and 17 . The first hinge opens at the intrados between arch bricks 16 and 17 in the ascendant branch at a load of $3.5 \mathrm{kN}$ with a downword displacement corresponding to $2.15 \mathrm{~mm}$, which is close to that noticed experimentally $(2.2 \mathrm{~mm},[6])$. The second crack appears at the extrados between bricks 11 and 12, while the third and the fourth hinges open respectively, at the extrados and at the intrados between vossouirs 6-7 and 20-21, around the peak phase, exactly as noticed in the experimentally. As in the experimental test, the peak load is equal to $5.8 \mathrm{KN}$. The numerical simulation provides a sudden decrease in the load after the peak value, which is not reflected in the experiment, and a corresponding underestimate of the load-displacement softening branch. 
It is noteworthy that backfill constrains displacements during the pre-peak phase and increases the load-carrying capacity due to its load spreading effect.

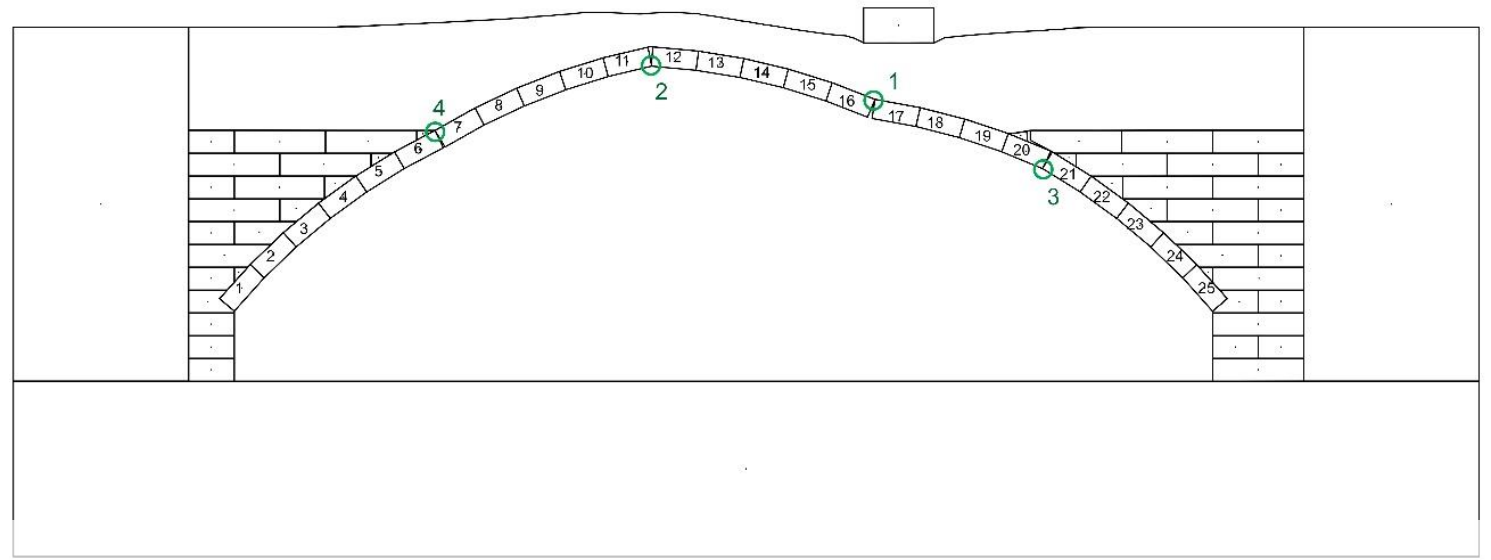

Figure 2. DEM failure mode and hinge formation order.
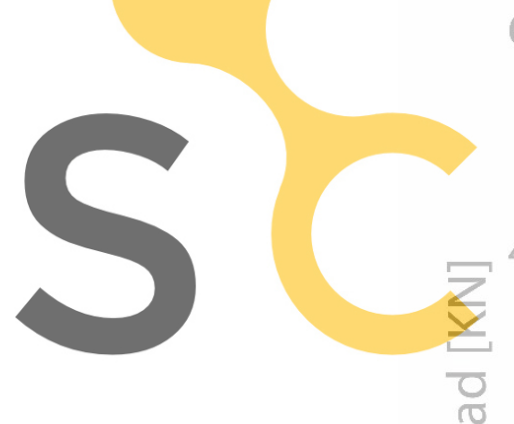

6
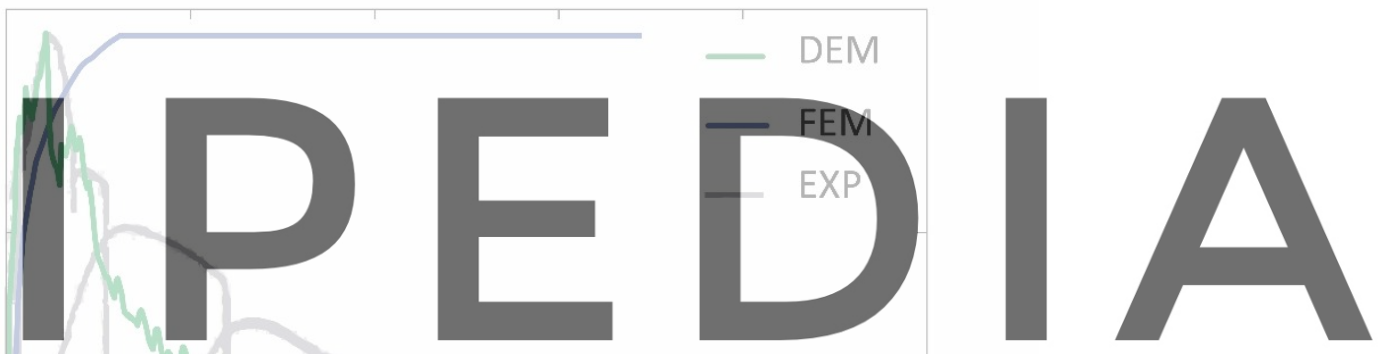

Register for free at https//www.scipedia.com to download the version without the watermark

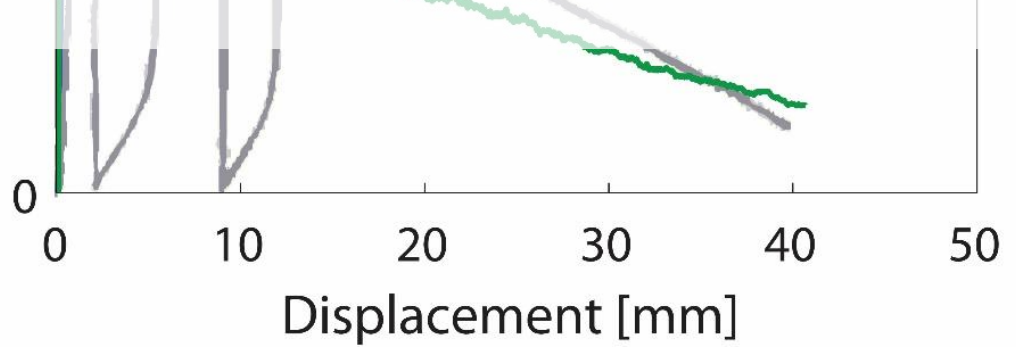

Figure 3. Load displacement curve of the Experimental test and the DEM-FEM modelling strategies.

\subsection{Overview of modelling with FEM}

The finite element model, adopted to describe the behaviuor of the vault, represents the masonry panel as an elasto-plastic homogenized Love-Kirchhoff elasto-plastic plate, with an associated flow-rule [4,5]. For further details, the readers can refer to the above aforementioned cited works $[4,5]$. While the mechanical behaviuor of the backfill material is modelled by 
considering it as a Mohr Coulomb medium. In Figure 4, the finite element discretization of the problem at hands in question is shown in Figure 5.

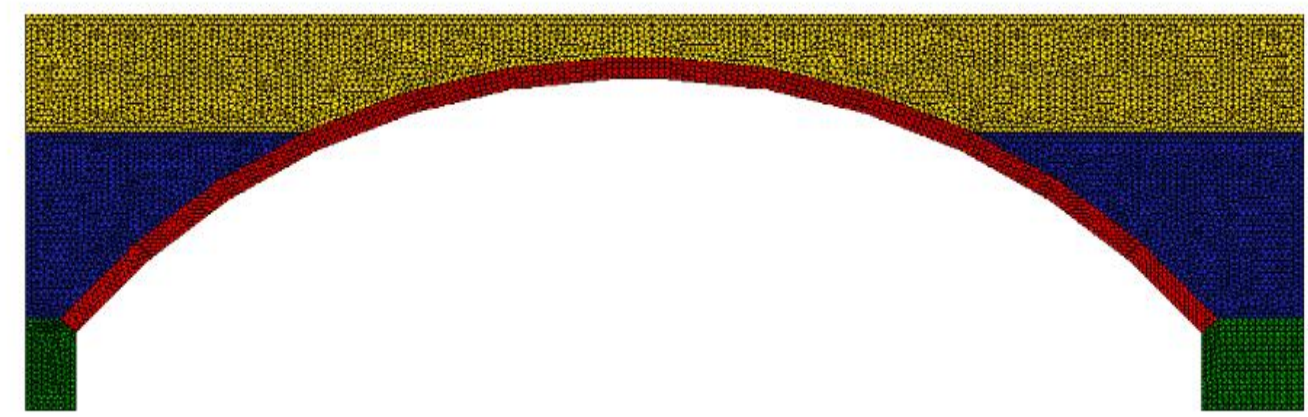

Figure 4: Finite element model.

The vault is discretized by means of triangular shell elements, but in this case the model is subject only to in-plane actions. In the same figure, the different colors correspond to the different masonry or back

According to $[4,5$ masonry are friction anc the mechanical parameters for baekfill materia angle of $31^{\circ}$ and $39^{\circ}$ is adopted, for masonry

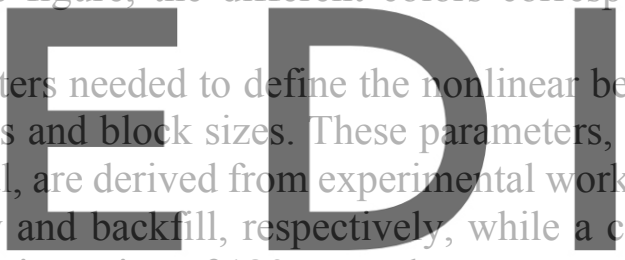
behaviour of
s, along with
ork: a friction
cohesion of zero is chosen for both masonry and backfill. Dimension of $120 \mathrm{~cm}$ and $55 \mathrm{~cm}$ are assumed for

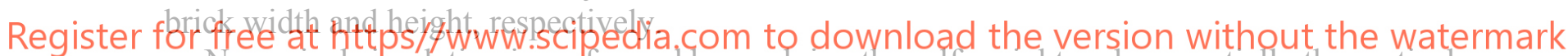
Numerical simulation is performed by applying the self-weight and sequentially the vertical force.

\subsubsection{Finite Element Results}

The results of the numerical simulation are shown in Figure 5, where the plastic strain distribution corresponding to the opening of the head joints at the collapse, i.e. after the developing of all the four hinges, are shown. The load baring capacity of the vault, provided by the finite element model is $5.6 \mathrm{KN}$ (Figure 3). According to homogenization theory, on which the finite model is based, the value provided is a lower bound. 


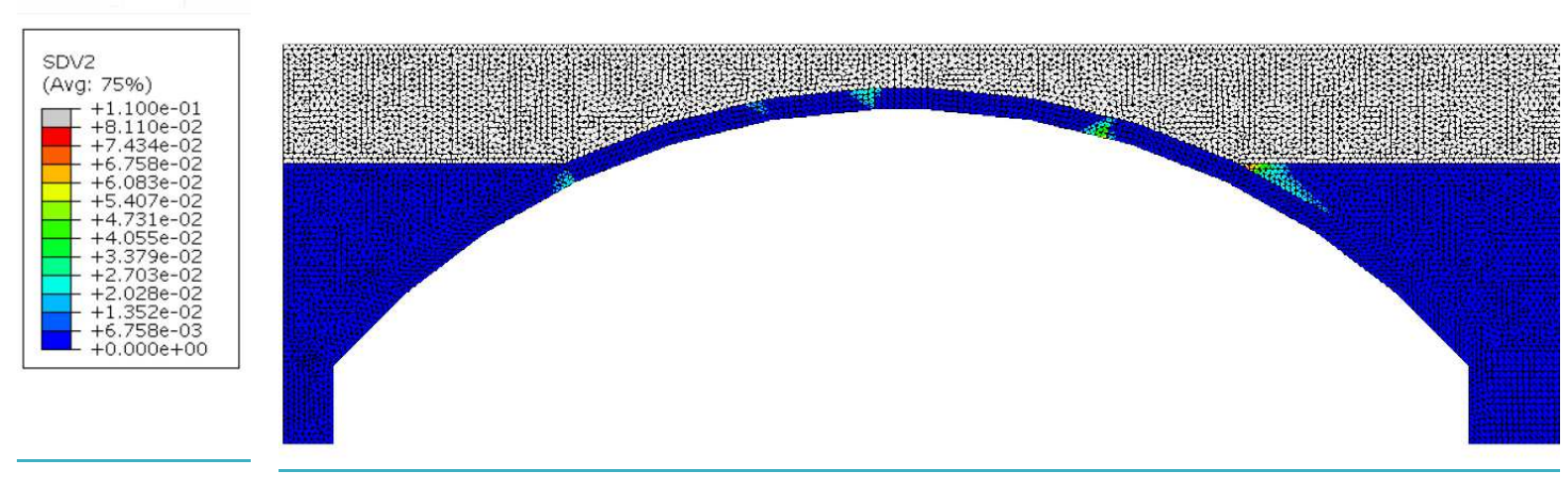

Figure 5: Plastic strain distribution after the hinge formation.

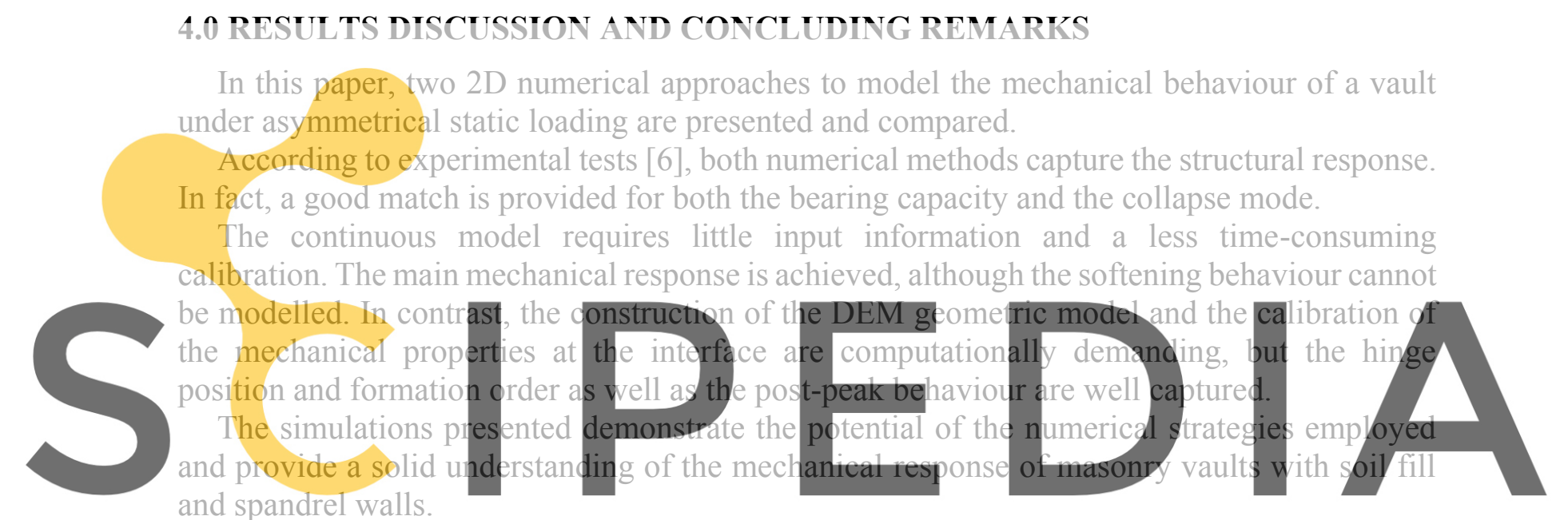

Register for free at httes /www.scipedia.com to download the version without the watermark

[1] Gesualdo A, Brandonisio G, De-Luca A, Iannuzzo A, Montanino A, Olivieri C. Limit analysis of cioister vauits: The case study of Palazzo Caracciolo di Aveliino. J Miech Mater Struct 2019;14:739-50. https://doi.org/10.2140/jomms.2019.14.739.

[2] Cavicchi A, Gambarotta L. Lower bound limit analysis of masonry bridges including arch-fill interaction. Eng Struct 2007. https://doi.org/10.1016/j.engstruct.2007.01.028.

[3] Gobbin F, de Felice G, Lemos J V. A Discrete Element Model for Masonry Vaults Strengthened with Externally Bonded Reinforcement Bonded Reinforcement. Int J Archit Herit 2020;00:1-14. https://doi.org/10.1080/15583058.2020.1743792.

[4] Malena M, Portioli F, Gagliardo R, Tomaselli G, Cascini L, de Felice G. Collapse mechanism analysis of historic masonry structures subjected to lateral loads: A comparison between continuous and discrete models. Comput Struct 2019;220:14-31. https://doi.org/10.1016/j.compstruc.2019.04.005.

[5] De Felice G, Malena M. Failure pattern prediction in masonry. J Mech Mater Struct 2019;14:663-82. https://doi.org/10.2140/jomms.2019.14.663.

[6] De Santis S, Roscini F, de Felice G. Full-scale tests on masonry vaults strengthened with Steel Reinforced Grout. Compos Part B Eng 2018;141:20-36. 
https://doi.org/10.1016/j.compositesb.2017.12.023.

[7] Cundall PA. A computer model for simulating progressive large-scale movements in blocky rock systems. Proocedings Symp. Int. Soc. Rock Mech. Nancy 2, 1971. https://doi.org/10.1016/j.optcom.2003.10.046.

[8] Itasca. UDEC (Universal Distinct Element Code), Version 6.0 2017.

[9] Detournay C, Dzik E. Nodal mixed discretization for tetrahedal elements. In: Group IC, editor. 4th Int. 397 FLAC Symp. Numer. Model. Geomech., Minneapolis, MN, USA: 2006.
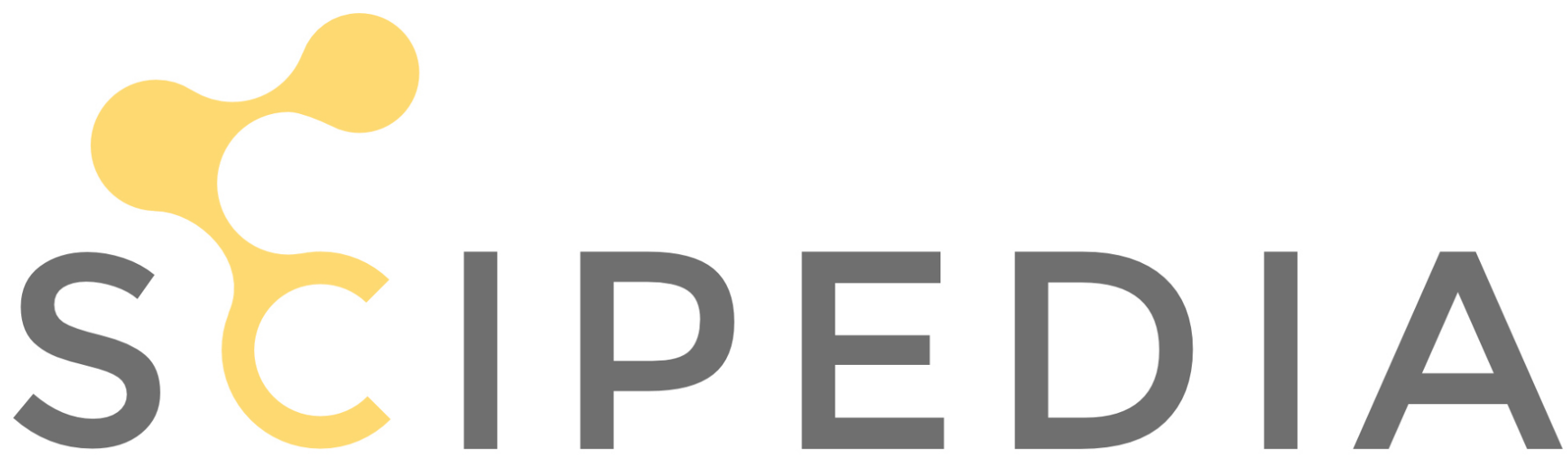

Register for free at https//www.scipedia.com to download the version without the watermark 